\title{
Comparison of Three Image Classification Methods in Urban Environment
}

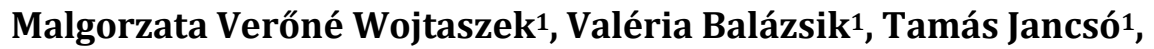 \\ Margit Horoszné Gulyás ${ }^{1}$, Qingyan Meng² \\ ${ }^{1}$ Alba Regia Technical Faculty, Obuda University, Székesfehérvár, Hungary \\ ${ }^{2}$ Institute of Remote Sensing and Digital Earth, Chinese Academy of Sciences, Beijing, China \\ Email: wojtaszek.malgorzata@amk.uni-obuda.hu
}

Received February 2015

\section{Abstract}

The article is dealing with different classification methods applied for urban aerial photos having visible and infrared channels. An accuracy assessment was carried out to compare the results gained from different classification methods.

\section{Keywords}

\section{Classification, Neuralnet, Segments, Land Cover}

\section{Introduction}

The introduced thematic maps are the first results of a two-year Chinese-Hungarian bilateral research project No. TÉT_12_CN-1-2012-0026 aiming the production of different thematic maps to characterize the urban ecological environment, the produced maps can be used for ecosystem restoration. At some Hungarian cities (Sopron, Szekesfehervar, Szombathely) we plan to examine the environmental conditions inside the urban area. Besides the remote sensing technology, we collect the reference data at some sample points from different cover types (like forest, grass, agricultural area, water surfaces, residential areas industrial zones, etc.). Based on the remote sensing classification and the gained sample data, we describe the ecological condition of the target cities.

Recently we can use only the existing data sources, since the hyper-spectral imaging will be carried out next spring, in 2011.

Urban land cover and land use data play an important role in ecological and environmental examinations. In several research studies remote sensing data are used as a source data, but the results are not quite satisfying for detailed land use detection in urban areas [1].

Many studies have been carried out to find an appropriate method to classify the high resolution remote sensing data [2] [3].

\section{Study Area and Pre-Processing Data}

\subsection{Introduction to the Study Area}

The target cities for investigation are Sopron, Szombathely and Szekesfehervar. These settlements have medium 
sized territory, the population is respectively 56,000, 80,000 and 105,000 (see Table 1). We can find common and different characteristics among them according to their construction features. All the three cities have a historical city centre with narrow streets, around these centres we can find housing estate and outskirt zones equally. Among the three cities the streets of Sopron downtown are the narrowest ones, then the next is Szekesfehervar, and the streets and spaces of the downtown of Szombathely are the widest ones. The topographical features of the inner-city of Szombathely and Sopron are similar, single quarters came into existence surrounded by hills having average altitudes of 220 meters above the sea level. The topographical features of Sopron are more diverse, the height differences inside the city are bigger than in case of Szombathely. Both cities are located at the western part of the country, so the Alps has an effect on their climate. The average precipitation is $700-800 \mathrm{~mm}$, which is $200 \mathrm{~mm}$ more comparing it with Szekesfehervar locating in the middle part of the country. The average yearly temperature of the two cities located near the western borderline of Hungary is $8-10 \mathrm{Co}$, which differs from Szekesfehervar's yearly average temperature of $10-12 \mathrm{Co}$. This fact is important, because the temperature can effect on the general condition of the vegetation. Due to this reason the appearance of vegetation on aerial photographs may show differences at each city. Szekesfehervar is located at the middle part of the country, on a plane area with an average altitude of 111 meters above the sea level. Its climate is drier, the average moisture in a year is between $500-600 \mathrm{~mm}$, this value is $200 \mathrm{~mm}$ less, than in the other two cities.

\subsection{Origin and Pre-Processing of Data}

In 2008 the inner part of the city Szekesfehervar was laser scanned and in parallel with the laser scanning a digital true ortho-photo was taken in visible and in NIR spectra. The images cover an area of $5 \mathrm{~km}^{2}$, but the images were taken in four tiles, therefore the first task was to compile a mosaic image of the taken images.

The ground resolution of the images is $0.5 \mathrm{~m}$. In the frame of the project an investigation was carried out to map the following categories: grass land, tree, water, tiled roof, flat roof, barren land, paving-stone and road. The Idirisi GIS software was used for producing the desired thematic map.

Other data sources used for investigation:

- Digital Terrain/Surface Model generated from LIDAR measuring data

- Field reference data (GPS)

- Vector data from Cadastre maps

- Attribute data gained from the municipalities

- Thematic data (climate, moisture etc.)

- Other statistical data.

\section{Materials and Methods}

Image classification was used to identify and classify pixels. It was performed on multi-channel data (visible and near infrared) and this process assigns to each pixel in an image a particular class based on statistical characteristics of the pixel values. The pixel based classification, segmentation and Neuralnet classification were done to map the land cover. The final result of the analysis consists of maps and statistical data.

\subsection{Pixel-Based Classification}

In supervised classification, the spectral features of some areas of known land cover types are extracted from the photo. Every pixel of the photo is then classified belonging to one of the classes depending on how close its spectral features are to the spectral features of the training areas. The mathematical methods we used in classification were the Maximum Likelihood Classifier (an unknown pixel can be classified by calculating for each

Table 1. Statistical data about the cities.

\begin{tabular}{ccccc}
\hline City & Inner City Area (ha) & Population & $\begin{array}{c}\text { Population Density for Inner City Area } \\
\left(\text { person/ } / \mathrm{km}^{2}\right)\end{array}$ & \begin{tabular}{c} 
Urban Green Area (ha) \\
\hline Sopron
\end{tabular} \\
Szombathely & 2349 & 59,980 & 392 & 913 \\
Székesfehérvár & 3062 & 79,440 & 385 & 242 \\
\hline
\end{tabular}


class with its probability values) and Minimum Distance Classifier.

According to the ground truth, eight classes were distinguished in this test: grass, forest, water, building area ( 2 classes: tiled and flat roof), barren land, paving stone and road.

\subsection{Segment-Based Classification}

Segmentation is a process by which pixels are grouped into segments according to their spectral similarity (Figure 4). Segmentation employs a watershed delineation approach to partition input imagery based on their variance. A derived variance image is treated as a surface image allocating pixels to particular segments based on variance similarity. Segment-based classification is an approach that classifies an image based on these image segments.

\subsection{Neuralnet Classification}

First step was to allocate the training areas inside the image by each thematic category. For finding the training areas both, the near infrared and the visible channel image were applied as well. In total 80 training areas were set.

Based on the training areas the spectral signature files were created for each thematic category containing the spectral and statistical characteristics.

The next step was to investigate the Neuralnet method. Figure 1 shows the parameters set during the Neuralnet based learning process.

The gained map was checked against the accuracy, and the maximum overall accuracy was achieved trying different parameters in the training phase of the Neuralnet method is $75 \%$. A segment of the produced thematic map is shown in Figure 2.

\section{Results}

In the Maximum Likelihood Classifier an unknown pixel can be classified by calculating for each class the probability belonging to each class. The Figure 3 shows the results of classification.

A supervised classification is based on the single value of pixel and does not utilize the spatial information within an object. Because of the complexity of surface features and the limitation of spectral information, the results of traditional classification methods can be mistaken, even it can give a confused classification. In our work we used the segment-based classification to compare the object-oriented one with pixel-based classification approach.

Before carrying out the segment-based classification, the classes (training area) were assigned on the image segments. The result of classification is shown in Figure 4. The Table 2 includes statistical data of the classification.

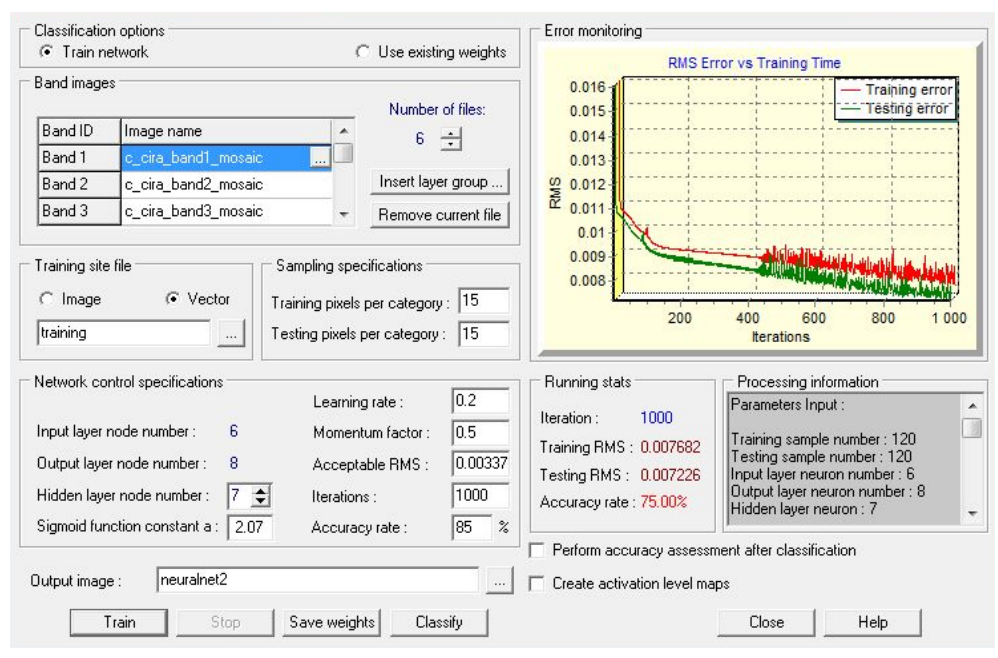

Figure 1. Set up of parameters at the NERUALNET classification. 


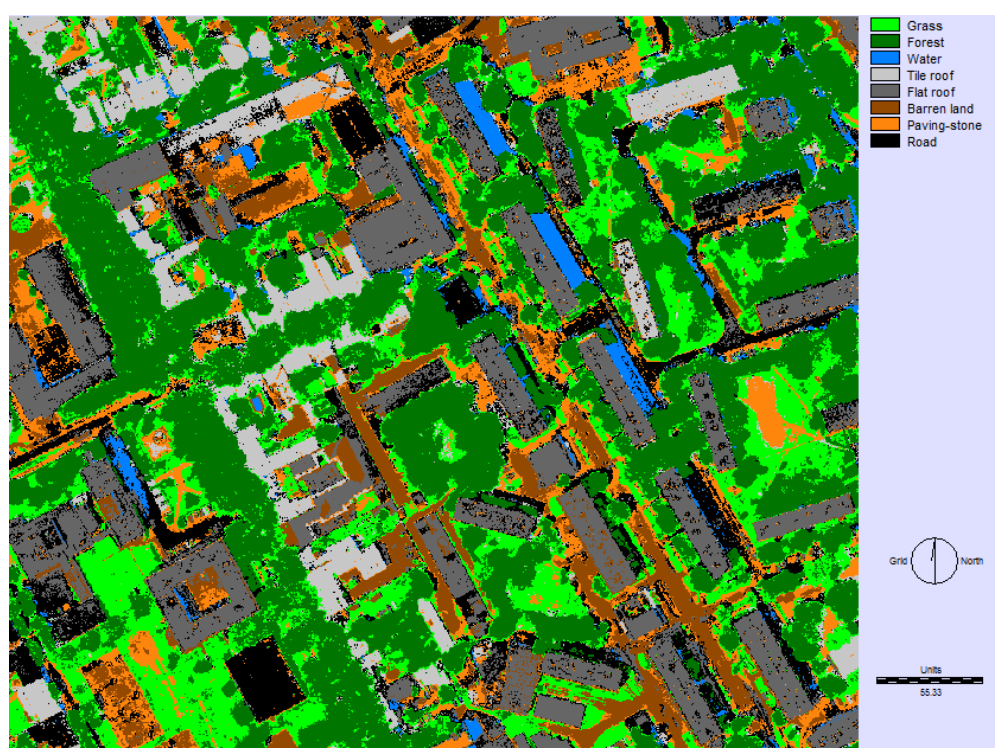

Figure 2. Result of the NERUALNET classification.

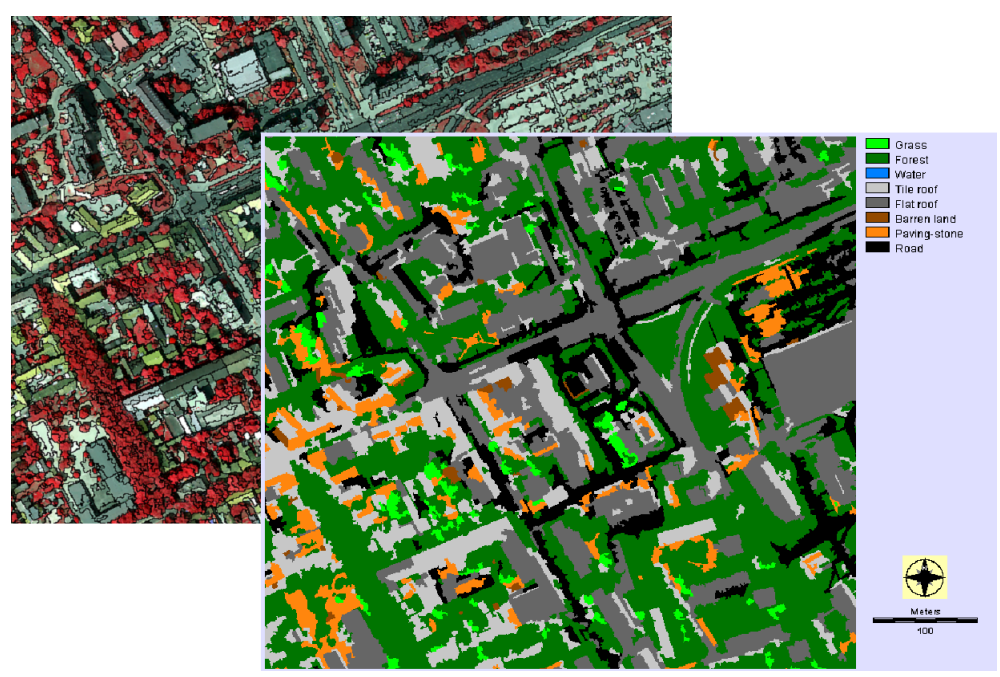

Figure 3. Land cover map of Szekesfehervar based on Maximum Likelihood method (fragment).

Table 2. The results of the segment-based and the pixel-based classification.

\begin{tabular}{cccc}
\hline Category & $\begin{array}{c}\text { Pixel-based classification } \\
\text { area (hectares) }\end{array}$ & $\begin{array}{c}\text { Object-oriented classification } \\
\text { area (hectares) }\end{array}$ & $\begin{array}{c}\text { Neuralnet classification } \\
\text { (hectares) }\end{array}$ \\
\hline 1. Grass & 35.7 & 12 & 88.3 \\
2. Forest & 165.9 & 198 & 106.2 \\
3. Water & 3.3 & 3 & 10.6 \\
4. Tile roof & 118.0 & 108.3 & 49.4 \\
5. Flat roof & 73.9 & 80.0 & 62.7 \\
6. Barren land & 13.3 & 8.7 & 43.1 \\
7. Paving-stone & 41.9 & 40.8 & 55.8 \\
8. Road & 40.2 & 40.6 & 76.1 \\
\hline
\end{tabular}




\section{Accuracy Assessment}

The results of the land cover classifications derived from remotely sensed data are compared by an accuracy assessment. The reference samples are ground truth data coming from the vector data from the cadastre map and the field reference data (classification inspections on the field, Figure 5). The error matrices have been generated. The assessment indicates the producer's and consumer's accuracy and overall accuracy in Table 3.

\section{Summary}

In our paper, we compared pixel-based classification, object-oriented segmentation and the Neuralnet classification approaches using multi-spectral air-photo in a small part of Szekesfehervar (Hungary). Analysing the results of accuracy assessment we can see that the overall accuracy in the three cases generally show similarity, the object-oriented classification produced more accurate results, than the other two methods. Looking the results of categories we have find differences especially in the following categories: tile roof, flat roof, paving-stone and road. The errors of omission and commission are high, and it is caused by the spectral similarity of categories.

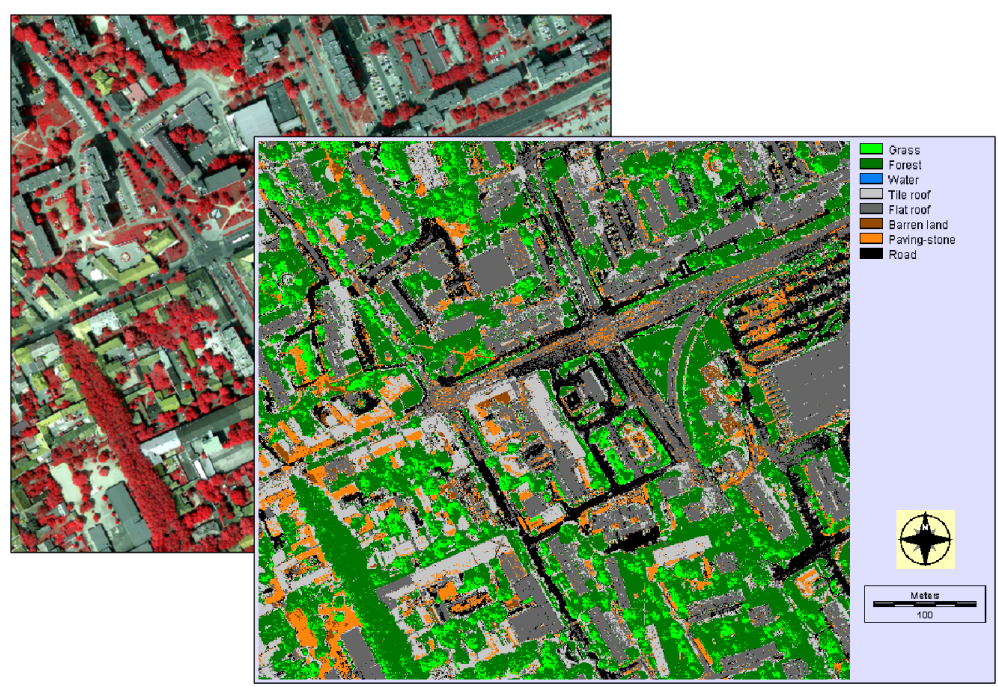

Figure 4. The aerial photo with segments (similarity tolerance: 30 ) and the results of the segment-based classification (fragment).

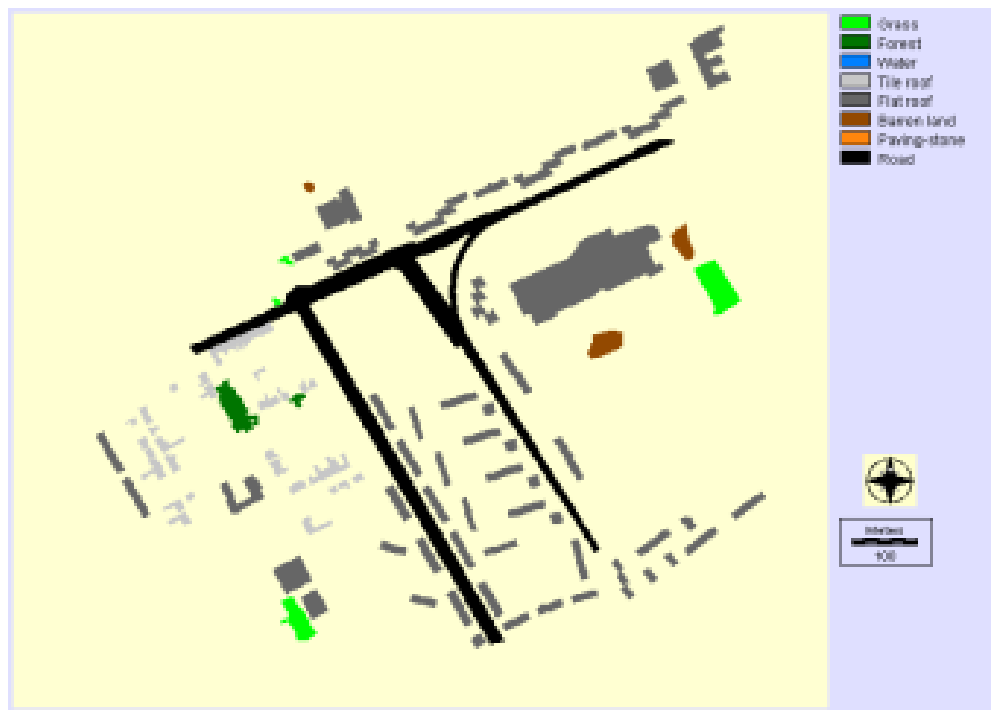

Figure 5. The reference data of the accuracy assessment (fragment). 
Table 3. Accuracy assessment results from the pixel-based and the segment-based classification.

\begin{tabular}{ccccccc}
\hline \multirow{2}{*}{ Category } & \multicolumn{2}{c}{ Pixel-based classification } & \multicolumn{2}{c}{ Object-oriented classification } & \multicolumn{2}{c}{ Neuralnet Classification } \\
\cline { 2 - 7 } & $\begin{array}{c}\text { Producer's } \\
\text { accuracy } \%\end{array}$ & user's accuracy \% & $\begin{array}{c}\text { Producer's } \\
\text { accuracy } \%\end{array}$ & User's accuracy \% & $\begin{array}{l}\text { Producer's } \\
\text { accuracy \% }\end{array}$ & $\begin{array}{c}\text { User's } \\
\text { accuracy \% }\end{array}$ \\
\hline 1. Grass & 93.8 & 73.0 & 35.2 & 79.1 & 77.4 & 53.1 \\
2. Forest & 90.5 & 21.2 & 94.3 & 16.5 & 94.4 & 26.7 \\
3. Water & 99.6 & 100 & 100 & 100 & 100 & 87.6 \\
4. Title roof & 53.9 & 32.5 & 57.2 & 46.5 & 69.9 & 78.6 \\
5. Flat roof & 81.2 & 76.1 & 90.4 & 75.2 & 78.0 & 77.4 \\
6. Barren land & 25.4 & 21.0 & 18.8 & 18.4 & 74.0 & 23.1 \\
7. Paving-stone & 53.2 & 14.3 & 69 & 28.8 & 83.0 & 21.6 \\
8. Road & 20.8 & 88.0 & 23.9 & 93.0 & 19.5 & 45.0 \\
\hline
\end{tabular}

The errors could be made better by applying more detailed categories. Even better results are expected by entering the hyper-spectral remote sensing data.

\section{Acknowledgements}

The research was carried out thanks to the image data offered by the Obuda University, Alba Regia Technical Faculty in the frame of the project No. TÉT_12_CN-1-2012-0026. The research was supported also by the following projects:

China National Natural Science Foundation with Project No. 41471310 Study on Urban Green Space Index Retrieval Model based on Airborne LiDAR;

Study on the urban imperious surface monitoring technique with hyper-spectral remote sensing data, 2012B091100219, Guang dong Province-Chinese Academy of Sciences Industry-Education-Research joint funding project;

Integrated geo-spatial information technology and its application to resource and environmental management towards the GEOSS (EU FP7 PIRSES-GA-2009-247608).

\section{References}

[1] Lu, D., Hetrick, S. and Moran, E. (2010) Land Cover Classification in a Complex Urban_Rural Landscape with QuickBird Imagery. Photogrammetric Engineering \& Remote Sensing, 76, 1159-1168. http://dx.doi.org/10.14358/PERS.76.10.1159

[2] Zhang, Y. (1999) Optimisation of Building Detection in Satellite Images by Combining Multispectral Classification and Texture Filtering, Journal of Photogrammetry \& Remote Sensing, 54, 50-60.

Fisher, H.E., Aron, A. and Brown, L.L. (2006) Romantic Love: A Mammalian Brain System for Mate Choice. Philosophical Transactions of the Royal Society: Biological Sciences, 361, 2173-2186.

[3] Fekete, I., Dezső, B., László, I. and Ócsai, K. (2008) The Role of Segmentation in the Thematic Clssification of Satellite Images. Informatika a felsőoktatásban 2008 konferencia elektronikus kiadványa, DE Informatikai Kar, Debrecen. 